\title{
KUALITAS PELAYANAN PASIEN DI RUMAH PERAWATAN USIA LANJUT KRISTEN BOGOR
}

\author{
Sosyati Ataupah*, Novita Verayanti Manalu \\ Fakultas Ilmu Keperawatan, Universitas Advent Indonesia, Jl. Kolonel Masturi No.288, Cihanjuang \\ Rahayu, Kec. Parongpong, Kabupaten Bandung Barat, Jawa Barat 40559, Indonesia \\ *rutaas081@gmail.com (+6281218449269)
}

\begin{abstract}
ABSTRAK
Rumah pelayanan dapat didefinisikan sebagai satu dari berbagai organisasi kesehatan yang fungsinya ialah menyediakan pelayanan yang baik pada semua pasien, terlebih untuk rumah pelayanana kesehatan untuk usia lanjut. Kepuasan pasien ini dianggap sebagai tingkatan atau respon perasaan dari pasien yang didapatkannya sesudah menerima hasil atau kinerja yang diberikan pada pasien tersebut. Penelitian ini dimaksudkan agar dapat menentukan kualitas pelayanan yang pasien pada Rumah Pelayanan Usia Lanjut Kristen Bogor tersebut dapatkan. Guna menentukan tingkatan kepuasan ini, terdapat lima indikator tertentu yang dijadikan sebagai penentu untuk kualitas layanan ini, diantaranya ialah empati (empathy), jaminan (assurance), daya tangkap (responsiveness), keandalan (reliability) dan juga bukti langsung (tangibles). Untuk penelitian ini memanfaatkan metode Deskriptif Kuantitatif. Dalam memilih sampel penelitian menggunakan teknik sampel Cluster Random Sampling, yang mana bahwa total Responden penelitian ialah 75 responden. Data penelitian ini diambil ialah berawal dari tanggal 15 Maret 2021 sampai 20 April 2021. Berdasarkan hasil penelitian ini dihasilkan bahwa varibael bukti langsung (tangible) didapatkan tingkatan kepuasan senilai 93,9\%, empati (Empathy) dihasilkan 68 responden penelitian (91,2\%), jaminan (assurance) dihasilkan 68 responden penelitian (91\%), daya tangkap (responsiveness) dihasilkan 68 responden penelitian $(91,2 \%)$ dan sedangkan untuk kehandalan (Reliability) dihasilkan 69 responden (91,3\%). Berdasarkan pada hasil penelitian ini dapat dihasilkan simpulan bahwa kualitas pelayanan Rumah Pelayanan Usia Lanjutan Kristen ini sangat bagus, yang mana bahwa rata-rata untuk tingkatan kepuasan yang diterima pasien ini ialah $91 \%$.
\end{abstract}

Kata kunci: deskripsi kuantitatif; kualitas pelayanan; rumah pelayanan

\section{THE SERVICE QUALITY OF PATIENTS IN THE CHRISTIAN ELDERLY HOME CARE IN BOGOR}

\begin{abstract}
A home care is one of the health organizations that provide the best service to each patient, especially for the elderly. Patient satisfaction is the patient's response after the patient received the product (goods / services) by comparing the performance or perceived results with the expectations. The aim of the study was to determined the quality of patient service in the Christian Elderly Home Care in Bogor. There are five indicators that determine service quality, including: Tangibles, Reliability, Responsiveness, Assurance, and Empathy. This study used quantitative descriptive method. The sample consisted of 75 respondents who were collected by using cluster random sampling technique. The data collection was taking place between 15 March and 20 April 2021. The results showed that the tangibles level of satisfaction was $93.9 \%$, the reliability was $91.3 \%$ (69 people), the responsiveness was $91.2 \%$ (68 people), the assurance was $91 \%$ (68 people), and the empathy was $91.2 \%$ (68 people). The result of the study showed that the service quality of the Chistian Elderly Home Care was excellent, with the average level of patient satisfaction $91 \%$.
\end{abstract}


Keywords: care home; quantitative description; service quality

\section{PENDAHULUAN}

Rumah sakit dapat didefinisikan dengan satu dari berbagai organisasi yang beroperasi pada bidang kesehatan. Saat ini banyak masyarakat yang membutuhkan layanan kesehatan dari rumah sakit dan atau berbagai organisasi layanan kesehatan yang lain. Rumah sakit di dalam bidang kesehatan mempunyai peranan yang fundamental dalam membantu atau meningkatkan kesehatan masyarakat secara umum, rumah sakit juga berperan sebagai satu dari berbagai sarana kesehatan yang menyediakan layanan kesehatan untuk masyarakat yang dimaksudkan untuk mempercepat peningkatan derajat kesehatan masyarakat (Aminah et al., 2017).

Rumah pelayanan dapat didefinisikan sebagai satu dari berbagai organisasi kesehatan yang fungsinya ialah menyediakan pelayanan yang baik pada semua pasien, terlebih untuk rumah pelayanana kesehatan untuk usia lanjut. Di dalam bidang kesehatan, pelayanan ini dapat dikatakan sebagai satu dari berbagai bentuk layanan yang begitu diperlukan masyarakat secara umum. Penggunaan layanan kesehatan pada rumah sakit ini menuntut atau meminta layanan yang memiliki kualitas yang baik, tidak hanya berkenaan dengan kesembuhan secara fisik semata, melainkan jua berkenaan dengan kepuasan dari pengetahuan, keterampilan dan juga sikap dari tenaga mendis yang memberikan pelayanan (Etlidawati, 2017).

Menurut pendapat (Christy, 2020) menjelaskan bahwa kualitas pelayanan dari suatu rumah sakit ini ialah sebagai refleksi atau cerminan atas keseluruhan sistem yang telah dioperasionalkan di dalamnya tersebut. Pelayanan yang memiliki kualitas baik ini tidak hanya berkenaan dengan layanan medis semata, melainkan juga dalam upaya penyelenggaraan rekam medis yang sebagai satu dari berbagai indikator untuk kualitas pelayanan dari rumah sakit tersebut.

Menurut Mulyadi, dkk (2013) dalam penelitian (Novita, Erpidawati, \& Elsi, 2019) menjelaskan bahwa rumah sakit ini didefinisikan sebagai suatu organisasi atau institusi layanan kesehatan untuk masyarakat yang memiliki karakteristik atau ciri khas tersediri yang memiliki keterkaitan hubungan yang erat dengan kemajuan teknologi, perkembangan ilmu pengetahuan kesehatan, dan juga kehidupan sosial-ekonomi masyarakat yang wajib untuk senantiasa bersedia menaikkan kualitas layanan agar menjadi lebih baik dan dapat terjankau masyarakat agar tercipta tingkatan kesehatan yang lebih baik.

Upaya untuk meningkatkan mutu kepuasan yang diterima setiap masyarakat yang datang ke rumah sakit, maka sangat penting sekali untuk meningkatkan kualitas pelayanan di rumah sakit. Menurut Susatyo Herlambang, 2016 dalam penelitian (Novita et al., 2019) Kualitas pelayanan menjadi hal yang penting di rumah sakit yang dimana jasa yang ditawarkan kepada masyarakat adalah pelayanan kesehatan. Sehingga pihak rumah sakit harus sadar akan kualitas yang ditawarkan kepada masyarakat dalam memberikan pelayanan kepada pengguna jasa kesehatan.

Menurut Yuliani (2015) menyatakan bahwa ertambanya kesadaran 
masyarakat tentang kesehatan mengakibatkan tuntutan agar dapat menaikkan layanan kesehatan. Satu dari berbagai upaya yang dapat dilaksanakan guna mencegah terjadinya keadaan ini ialah bahwa rumah sakit wajib untuk mampu menjaga dan mempertahankan mutu layanannya, dengan demikian hal ini akan menyebabkan pasien yang sudah pernah merasakan layanan tersebut ingin datang kembali jika memang memerlukan layanan kesehatan di lain hari.

Dengan tuntutan masyarakat yang kian meningkat untuk layanan kesehatan yang disediakannya tersebut, dengan ini fungsi pelayanan kesehatan dapat di tingkatkan untuk memberikan mutu kepuasan kepada pasien. Kemampuan rumah sakit untuk dapat memberikan kepuasan kepada setiap pasien. Umumnya pasien mendambakkan bahwa produk atau layanan jasa yang dinikmati atau diterimanya tersebut dengan layanan yang memuaskan dan baik. Merujuk pernyataan yang dikemukakan (Zaniarti, 2011) menjelaskan bahwa kepuasan pelanggan dapat didefinisikna sebagai tingkatan perasaan atau respon pelanggan yang didapatkan sesudah pelanggan tersebut menerima layanan jasa dengan cara mengkomparasikan antara hasil ataupun kinerja yang dirasakannya tersebut dengan harapan yang dimiliki sebelumnya. Jika hasil atau kinerja yang dirasakannya tersebut lebih rendah dibandingkan dengan harapannya, dengan demikian pasien tersebut akan kurang puas, tidak puas dan bahkan kecewa, begitupun sebaliknya.

Menurut Zeithaml, Bery, dan Parasuraman dalam Supranto (2001) dalam penelitian (Sudibyo, 2014) menyebutkan bahwa terdapat lima indikator yang dijadikan sebagai penentu atau pengukur dari kualitas layanan ini, antara lain ialah: 1) Bukti Langsung (Tangibles), yang mencangkup dengan sarana komunikasi, pegawai, perlengkapan, dan juga fasilitas fisik; 2) Keandalan (Reliability), diartikan sebagai kemampaun atau kapasitas dalam menyediakan layanan sebagaimana yang dijanjikan dengan memuaskan, segera dan akurat; 3) Daya Tanggap (Responsiveness), yakni keinginan atau kerelaan dari para pegawai ataupun staf dalam memberikan bantuan atau pertolongan pada pasien atau pelangan dengan cara menyediakan layanan secara tanggap; 4) Jaminan (Assurance), dalam hal ini meliputi dengan kesopanan, kemampuan, pengetahuan dan juga sifat yang dapat dipercaya yang dimiliki oleh para pegawai ataupun staf yang terbebas dari keraguraguan, bahaya dan juga risiko; 5)Empati (Empathy), ini mencangkup dengan memahami kebutuhan pasien, perhatian pribadi, komunikasi yang baik dan juga kemudahan dalam melaksanakan interaksi.

\section{METODE}

Jenis penelitian yang digunakan dalam penelitian ini adalah analisis Deskriptif Kuantitatif. Pemilihan sampel dilakukan dengan teknik sampel Cluster Random Sampling. Pengambilan data dilakukan dengan cara membagikan kuesioner kepada setiap pasein dan tenaga kerja yang ada di Rumah Sakit Pelayanan Usia Lanjutan Kristen Bogor. Pembagian kuesioner dilakukan mulai tanggal 15 Maret 2021 hingga tanggal 20 April 2021 dengan jumlah sampel berjumlah 75 orang.

Ada pun kriteria Inklusi penelitian ini terdiri dari staf medis, staf non medis, dan pasien. Sedangkan untuk kriteria eksklusi adalah menghilangkan nilai 
variabel pada subjek yang tidak di isi oleh setiap responden. Instrumen yang digunakan dalam penelitian untuk mengukur tingkat kualitas pelayanan terdiri dari 33 pertanyaan dengan lima indikator kualitas pelayanan dengan pilihan jawaban yaitu; Sangat Tidak Baik $=1$, Tidak Baik $=2$, Kurang Baik $=3$, Baik $=4$, dan Sangat Baik $=5$.
Penelitian yang dilakukan penulis telah mendapatkan surat keterangan layak etik dengan nomor: No.143/KEPKFIK.UNAI/EC/III/21.

\section{HASIL}

Hasil penelitian yang didapatkan oleh penulis, didapati hasil seperti tabel berikut ini.

Tabel 1.

Karakteristik Responden $(n=75)$

\begin{tabular}{|c|c|c|}
\hline Karakteristik & $\mathrm{f}$ & $\%$ \\
\hline \multicolumn{3}{|l|}{ Usia } \\
\hline $15-24$ Tahun & 8 & 10,7 \\
\hline 25 - 34 Tahun & 16 & 21,2 \\
\hline 35 - 44 Tahun & 14 & 18,7 \\
\hline $45-54$ Tahun & 13 & 17,4 \\
\hline $55-64$ Tahun & 6 & 8 \\
\hline $65-74$ Tahun & 5 & 6.6 \\
\hline 75 - 84 Tahun & 9 & 11,9 \\
\hline 85 - 94 Tahun & 3 & 4 \\
\hline \multicolumn{3}{|l|}{ Jenis Kelamin } \\
\hline Laki-Laki & 29 & 38,7 \\
\hline Perempuan & 46 & 61,3 \\
\hline \multicolumn{3}{|l|}{ Pendidikan } \\
\hline SD & 6 & 8 \\
\hline SMP & 20 & 26 \\
\hline SMA/SMK/STM & 33 & 44 \\
\hline D2/D4 KOMPUTeR & 5 & 7 \\
\hline SPG/SPK & 3 & 4 \\
\hline S1 & 1 & 1,3 \\
\hline $\mathrm{S} 2$ & 2 & 2,7 \\
\hline D4 Perawat & 1 & 1,3 \\
\hline \multicolumn{3}{|l|}{ Pekerjaan } \\
\hline Staf Medis & 18 & 24 \\
\hline Staf Non Medis & 23 & 30,5 \\
\hline Karyawan Swasta & 12 & 16 \\
\hline Ibu Rumah Tangga & 3 & 4 \\
\hline
\end{tabular}


Tabel 2.

Presentase Indikator Penentu Kualitas Pelayanan

\begin{tabular}{lcccccc}
\hline Variabel & Tangibles & Relibability & Responsiveness & Assurance & Empathy & $\%$ \\
\hline Sangat Tidak Baik & 0 & 0,3 & 0 & 0,43 & 1,3 & 0,43 \\
Tidak Baik & 0,13 & 0,7 & 0 & 0 & 0 & 0 \\
Kurang Baik & 2,5 & 5 & 6,12 & 5,1 & 1,6 & 5,1 \\
Baik & 68,7 & 67,7 & 68 & 61,33 & 70,38 & 61,33 \\
Sangat Baik & 25,2 & 23,6 & 23,2 & 28,88 & 19,98 & 28,88 \\
\hline
\end{tabular}

Menurut jenis kelamin responden dari penelitian yang dilakukan ini deketahui bahwa lebih besar responden penelitian ini adalah perempan sebayak $61,3 \%$ dan laki-laki sebanyak $38,7 \%$ ini berdasarkan jumlah kariawan dan pasien Rumah Perawaan Usia Lanjut Kristen Bogor 2020 jumlah kariawan dan pasien wanita lebih banyaak dari pria. Karakteristik responden berdasarkan pendidikan adalah SMA/SMK/STM 44\% berdasarkan hal tersbut dapat dilihat bahwaa kariawan yang bekerja kariawan yang perpendidikan cukup baik. Berdasarkan penelitian yang dilakukan responden diketahui bahwa sebagian besar responden pada penelitian iniadalah sttaf nonmedis sebesar 30,5\%. Dan sesuai penelitian yang dilakukan Sosyai Ataupah yang dilakukaan di Rumah Perawatan Usia Lanjut Kristen Bogor yang menyaatakan $24 \%$ adalah staf medis

Berdasarkan hasil penelitian yang dilakukaan ini sebagian besar responden dalam penelitian ini mengatakan pelayanan yang diberikan oleh Rumah Perawatan Usia Lanjut Kristen Bogor sangat baik yaitu sebesar 25,2\% berdasarkan profil Rumah perawatan Usia Lanjut Kristen Bogor 2020,menunjukkan pelayanan yang baik $68,7 \%$ sedangkan 2,5\% mengaak pelayanan Rumah Perawatan Usia lanjt Kristen Bogor kurang bak dan 0,3\% mengatakan kurang baik dan $0 \%$ sangat tidak baaik ini menunjukkan bahwa pelayanan yang dilakukan di Rumah
Perawatan Usia Lanjut Kristen Bogor sangat baik dan pasien merasa puas.

Berdasarkan relibability bahwa $67,7 \%$ responden merasa pelayanan yang diberikan di rumah pelayanan usia lanjutan Kristen di Bogor merasa Baik, 2020, 23,6\% responden merasakan pelayanan yang diberikan Sangat Baik,

Berdasarkan hasil penelitian Responsiveness sebagian besar respoden pada penelitiaan ini adalah $68 \%$ dalam mengatakan Baik sedangkan 23,2\% mengatakan sangat Baik dan berdasarkan profil pelayana kesehatan Rumak Perawatan Usia Lanjut Kristen Bogor,2019 sedangkan menurut profil 2020, 5\% responden mengatakan pelayanan kurang baik ini menunjukkan adanya peningkatan kualitas pelayanan di Rumah Perawatan Usia Lanjut Kristen Bogor.

Berdasarkan hasil Assurance didapati $61,33 \%$ responden merasa pelayanan yang diberikan di rumah pelayanan usia lanjutan Kristen di Bogor merasa Baik, $8,88 \%$ responden merasakan pelayanan yang diberikan Sangat Baik.

Hasil penelitian variabel Empathy $70,38 \%$ responden merasa pelayanan yang diberikan di rumah pelayanan usia lanjutan Kristen di Bogor merasa Baik, 19,98\% menunjukkan bahwa adanya peningkatan kualitaas pelayanan yang diberikan di Rumah Perawatan Usia Lanjut Kristen Bogordan pasien merasa "puas. 


\section{PEMBAHASAN}

Kepuasan pasien ini diartikan sebagai cerminan atau refleksi atas layanan kesehatan yang diterimanya. Kualitas layanan kesehatan ini merujuk terhadap tingkatan kesempurnaan layanan kesehatan dalam menyebabkan timbulnya perasaan yang puas terhadap diri dari semua pasien (Supartiningsih, 2017). Berdasarkan penelitian didapatkan bahwa rata-rata tingkat kepuasan di Rumah Perawatan Usia Lanjutan Kristen di Bogor dengan variabel fisik (tangible) diperoleh tingkat kepuasan sebesar 93,9\% (71 orang). Hal ini menunjukan bahwa responden sudah merasa puas terhadap penampilan fisik yang diberikan oleh petugas yang ada di rumah perawatan. Penampilan yang yang diberikan perawata dan atau petugas medis lainnya rapi dan bersih. Ruang perawatan yang nyaman, penampilan dokter yang bersih dan rapi dan alat makan dan minum bersih.

Penelitian ini didukung oleh (Indriani, 2016) dalam penelitiannya yang menunjukan bahwa tingkat kepuasan pasien yang ada di rumah sakit Santo Borromeus Bandung didapat bahwa 99\% responden merasa puas terhadap pelayanan yang diberikan. Namun, penelitian ini berbanding terbalik dengan penelitian yang dilakukan oleh (Kurniasari, 2016) yang menyatakan bahwa tingkat kepuasan di Rumah Sakit Sido Waras hanya mencapai 46,6\% (40 orang) dengan kategori puas terhadap pelayanan yang diberikan.

Penelitian ini berbanding terbalik dengan penelitian yang dilakukan oleh (Septiani, 2016) yang mendapatkan hasil bahwa tingkat kepuasan dengan ketegori tangible terhadap kualitas pelayanan di IGD RSUD Sumedang hanya sebesar $32 \%$, sedangkan tingkat ketidak puasan pesien sebesar $68 \%$. Tingkat ketidak puasan pasien terhadap pelayanan yang diberikan karena kurangnya fasilitas alat-alat medis, kurang nyamannya ruangan IGD, dan penampilan perawat kurang rapi dan bersih.

Menurut pendapat (Yola \& Budianto, 2016) dalam penelitiannya memperlihatkan bahwa dimensi fisik ini memberi pengaruh terhadap kepuasan pelanggan, hal ini disebabkan bahwa pada dasarnya suatu perusahaan tersebut berlokasi pada lingkunganyang rumit dan juga dinamis, dengan demikian perusahaan tersebut musti lebih unggul dibandingkan yang lainnya.

Tingkat kepuasan berdasarkan analisis yang dilakukan terhadap kehandalan (Reliability) terdapat 69 orang $(91,3 \%)$ merasa bahwa pelayanan yang diberikan dalam hal kehandalan di rumah palayana merasa puas. (Indriani, 2016) mendapatkan hasil bahwa pada variabel kehandalan diperoleh tingkat kepuasan sebesar 94\% dengan indeks kenyataan sebesar 3,18 dan indeks harapan sebesar 3,378. Tingkat kehandalan yang diperolah karena memiliki tenaga medis yang sudah diakui oleh Lembaga pendidikan dalam dan luar negeri. Perawat juga selalu memberikan laporan yang sesuai dengan detail yang diperoleh kepada dokter. Perawat selalu memberikan obat yang sesuai prosedur pemberian obat.

Tingkat kepuasan berdasarkan analisis yang dilakukan pada variabel Responsiveness terdapat 68 orang $(91,2 \%)$ merasa puas terhadap pelayanan yang diberikan dalam hal daya tanggap di rumah pelayanan kesehatan usia lanjutan Kristen di Bogor. (Indriani, 2016) untuk variabel daya tanggap (responsiveness) 
didapatkan tingkatan kepuasan senilai 93\%, dengan indeks kenyataan senilai 3,153 dan sedangkan untuk indeks harapan senilai 3,394. Dengan ini memperlihatkan bahwa tingkatan kepuasan dari responden penelitian pada daya tanggap perawat ini puas pada aspek daya tanggap perawat yang ada pada Instalasi Gawat Darurat sekarang ini.

Tingkat kepuasan dengan variabel Assurance didapati hasil bahwa 68 orang (91\%) merasa Puas terhadap pelayanan yang diberikan dalam hal jaminan. Menurut Indriani (2016) menyebutkan bahwa variabel jaminan (assurance) didapatkan tingkatan kepuasan senilai 97\%. Dengan ini memperlihatkan bahwa kepuasan dari responden penelitian pada jaminan pelayanan perawat ini sudah lebih tinggi diperbandingkan dengan rata-rata tingkatan kepuasan responden penelitian yang sudah puas pada aspek jaminan pelayanan perawat yang diberikan Instalasi Gawat Darurat sekarang ini. Hal ini memperlihatkan bahwa kepuasan responden penelitian pada jaminan pelayanan perawat telah lebih tinggi diperbandingkan dengan rata-rata tingkatan kepuasan dari responden penelitian yang sudah puas pada aspek jaminan pelayanan perawat yang diberikan Instalasi Gawat Darurat sekarang ini.

Tingkat kepuasan dengan variabel Empathy didapati hasil bahwa 68 orang $(91,2 \%)$ merasa puas terhadap pelayanan yang diberikan dalam hal empati. (Indriani, 2016) Pada variabel empati (empathy) diperoleh tingkat kepuasan sebesar 95\% dengan indeks kenyataan sebesar 3,111 dan indeks harapan sebesar 3,263. Untuk meningkatkan tingkat kepuasan parlu dilakukannya penganganan yang lebih kepada setiap pasien yang memiliki kriteria ATS sehingga keluarga pasien dapat mengetahui dengan cepat apakah pasien mengalami gejala ATS atau tidak.

Hal ini memperlihatkan bahwa tingkatan kepuasan dari responden penelitian pada empati perawat puas terhadap 76 aspek empati perawat yang ada pada Instalasi Gawat Darurat sekarang ini. Sedangkan menurut penelitian (Siti \& Dody, 2019) didapati hasil bahwa terdapat $68,9 \%$ responden yang merasa puas terhadap pelayanan yang diberikan dengan kategori empati di instalasi gawat darurat.

\section{SIMPULAN}

Rata-rata tingkat kepuasan pasien yang ada di Rumah Pelayanan Usia Lanjutan Kristen Bogor adalah sebesar 91\%. Dengan tingkat kepuasan diangka $91 \%$ maka dapat dipastikan bahwa kualitas pelayanan yang diberikan kepada pasien yang ada di Rumah Pelayanan Usia Lanjutan Kristen sangat bagus. Penelitian hanya dilakukan untuk mengetahui kualitas pelayanan kepada pasien dengan menggunakan metode Deskriptif Kuantitatif.

\section{DAFTAR PUSTAKA}

Aminah, S., Cahyono, D., \& Herlambang, T. (2017). Pengaruh Mutu Pelayanan Dan Citra Rumah Sakit Terhadap Loyalitas Pasien Serta Kepuasan Pasien Sebagai Intervening Di Instalasi Peristi Rsd Dr. Soebandi Jember. Jurnal Sains Manajemen Dan Bisnis Indonesia, 7(2), 232-256. Retrieved From Http://Jurnal.Unmuhjember.Ac.Id/I ndex.Php/Smbi/Article/View/1234

Christy, J. (2020). Mutu Pelayanan Petugas Rekam Medis Terhadap Tingkat Kepuasan Pasien Bpjs 
Rawat Jalan Di Rumah Sakit Umum Ipi Medan Tahun 2019. Jurnal Ilmiah Perekam Dan Informasi Kesehatan Imelda, 5(2), 181-186.

Etlidawati, Dan D. Y. . (2017). Hubungan Kualitas Mutu Pelayanan Kesehatan Dengan Kepuasan Pasien Peserta Jaminan Kesehatan Nasional. Universitas Muhammadiyah Purwokerto, Jawa Tengah. Jurnal Ilmiah Ilmu - Ilmu Kesehatan, 15(3), 142-147.

Indriani, M. Y. (2016). Analisa Tingkat Kepuasan Keluarga Tentang Pelayanan Perawat Di Instalasi Gawat Darurat Rumah Sakit Santo Borromeus Bandung Oleh. 71-81.

Kurniasari, R. (2016). Hubungan Antara Level Emergency Severity Index (Esi) Dengan Kepuasan Pasien Di Instalasi Gawat Darurat Rumah Sakit Sido Waras. Jurnal Administrasi Kesehatan Indonesia, 4(2), 97. Https://Doi.Org/10.20473/Jaki.V4i 2.2016.97-106

Novita, S. L., Erpidawati, \& Elsi, S. (2019). Hubungan Kualitas Layanan Terhadap Kepuasan Pasien. Jurnal Menara Medika, 1(2), 8 .

Septiani, A. (2016). Pengaruh FaktorFaktor Kualitas Pelayanan Terhadap Kepuasan Pasien Di Instalasi Gawat Darurat Rsud Kabupaten Sumedang. Coopetition, Vii(Maret), 1-21.

Siti, N., \& Dody, S. (2019). Gambaran Tingkat Kepuasan Pasien Terhadap Pelayanan Perawat Di Instalasi Gawat Darurat Siti Nurhidayah 1 , Dody Setyawan 2. Xi(2).
Sudibyo, A. R. (2014). Hubungan Antara Kualitas Pelayanan Dengan Kepuasan Pasien Terhadap Pelayanan Di Rsia Srikandi Ibi Jember Tahun 2014.

Supartiningsih, S. (2017). Kualitas Pelayanan An Kepuasan Pasien Rumah Sakit: Kasus Pada Pasien Rawat Jalan. Jurnal Medicoeticolegal Dan Manajemen Rumah Sakit 10.18196/Jmmr.2016, 6(1), 9-15. Https://Doi.Org/10.18196/Jmmr.61 22

Yola, M., \& Budianto, D. (2016). Analisis Kepuasan Konsumen Terhadap Kualitas Pelayanan Dan Harga Produk Pada Supermarket Dengan Menggunakan Metode Importance Performance Analysis (Ipa). Jurnal Optimasi Sistem Industri, $\quad 12(1), \quad 301$. Https://Doi.Org/10.25077/Josi.V12 .N1.P301-309.2013

Yuliani, U. (2015). Hubungan Kualitas Pelayanan Dengan Kepuasan Pasien Rawat Inap Di Rsud Dr. Sayidiman Magetan Skripsi. Skripsi.

Zaniarti, D. (2011). Hubungan Kualitas Pelayanan Kesehatan Dengan Kepuasan Pasien Rawat Inap Jaminan Kesehatan Masyarakat Di Rumah Sakit Umum Daerah Salatiga. Fakultas Ilmu Pendidikan Universitas Negeri Semarang, 1164. 